\title{
Serving underserved transplant recipients: experience of the Medication Access Program
}

\author{
This article was published in the following Dove Press journal: \\ Patient Preference and Adherence \\ 2 May 2014 \\ Number of times this article has been viewed
}

\author{
Christina A Spivey' \\ Marie A Chisholm-Burns' \\ Charlene Garrett ${ }^{2}$ \\ Kenneth M Duke ${ }^{2}$ \\ 'University of Tennessee College \\ of Pharmacy, Memphis, TN, USA; \\ ${ }^{2}$ University of Georgia College \\ of Pharmacy, Athens, GA, USA
}

Objective: Programs have been established to help underserved, solid-organ transplant recipients and other patient populations address the burden of medication regimen costs. The purpose of this study was to describe one such program, the Medication Access Program (MAP), and the population of solid-organ transplant recipients it serves. An additional objective was to compare characteristics of recipients whose MAP enrollment was continued versus those who were discontinued during the annual re-enrollment period.

Methods: Enrollment into MAP is based on referral from a pharmacist or another health care professional/transplant team member. To enroll, a recipient must complete an application which includes information about demographics, health care coverage, income, and medication regimen. To maintain enrollment, patients must complete a renewal application on an annual basis. Data were collected from renewal applications for 2012 and 2011 (for those who did not return the 2012 renewal applications). Chi-square analyses and Student's $t$-test for independent samples were conducted to compare the characteristics of those who renewed their MAP enrollment in 2012 and those who were discontinued because they did not return the renewal application. Multivariate stepwise logistic regression was conducted to determine variables predictive of MAP continuation status.

Results: In total, 246 recipients were included. The majority qualified for Medicare (67.9\%), did not qualify for Medicaid (69.9\%), and did not have private health care coverage $(63.8 \%)$. Significantly more continued recipients qualified for Medicare compared to discontinued recipients $(P=0.002)$. Discontinued recipients had a greater number of past discontinuations than continued recipients $(P=0.01)$. In the logistic regression analysis, qualifying for Medicare was significantly associated with continuation status $(P=0.001)$.

Conclusion: MAP is designed to increase medication access for low-income solid-organ transplant recipients through enrollment into medication assistance programs, education regarding medication therapy, and availability of medication assistance programs. Health care providers should use historical monitoring to identify high risk patients and implement programs that will facilitate continuity of care.

Keywords: health care access, solid-organ transplant, medication

\section{Introduction}

Immunosuppressant therapy (IST) adherence plays a critical role in maintaining graft function following solid-organ transplantation. However, according to a metaanalysis by Dew et $\mathrm{al}^{1}$ IST nonadherence occurs in $22.6 \%$ of solid-organ transplant recipients on an annual basis, and underserved transplant recipient groups such as low income patients and minorities are particularly vulnerable to increased risk of IST nonadherence. ${ }^{2-5}$ Consequences of nonadherence to IST may be severe, including graft rejection and failure. For example, in the renal transplant population, a metaanalysis by Denhaerynck et al found that IST nonadherence contributed to $20 \%$ of late acute rejection episodes and $16 \%$ of graft losses. ${ }^{6}$ Barriers to adherence among
Correspondence: Marie A Chisholm-Burns University of Tennessee College of Pharmacy, 88I Madison Ave, Ste 264, Memphis, TN 38I63, USA

$\mathrm{Tel}+\mathrm{I} 901448-7|4|$

$\mathrm{Fax}+$ I 90I 448-7053

Emailmchisho3@uthsc.edu submit your manuscript $\mid$ www.dovepress.com

Dovepress

http://dx.doi.org/1 0.2147/PPA.S63133
Patient Preference and Adherence 20|4:8 613-6।9 
solid-organ transplant recipients are numerous and include the complexity of medication regimens, the need to adhere to regimens for as long as they maintain the transplanted organ, and the high cost of IST and other medications needed to treat comorbid conditions. ${ }^{7}$

In 2011, estimated costs of outpatient medication regimens for solid-organ transplant recipients ranged from $\$ 18,200$ $\$ 34,600$, depending on the transplanted organ. ${ }^{8}$ Thus, medication regimen costs represent a significant burden to solid-organ transplant recipients. Although Medicare pays for $80 \%$ of the cost of outpatient IST for the first 36 months following transplantation (note, those over 65 years of age and those who are disabled are eligible for lifetime Medicare coverage), many recipients may be unable to afford the $20 \%$ co-payment required to obtain IST. ${ }^{9,10}$ They must also identify other means of covering medication expenses when their 36-month Medicare eligibility expires. A survey of renal transplant recipients conducted by Gordon et al noted that $31 \%$ reported IST cost had a somewhat to great negative impact on their lives and 29\% experienced general financial strain posttransplant. ${ }^{11}$ Likewise, a survey of liver and renal transplant recipients found that $40.6 \%$ experienced financial difficulties secondary to transplantation, and approximately $47 \%$ of the sample reported having less monthly income than in the year preceding the transplant surgery. ${ }^{12}$ These studies suggest that financial hardship is commonplace among solid-organ transplant recipients and may have an adverse effect on their ability to acquire needed medication.

Increasingly, programs have been established to help underserved, solid-organ transplant recipients and other patient populations address the burden of medication regimen costs. ${ }^{13-18}$ Such programs improve patient access through enrollment in pharmaceutical manufacturers' medication assistance programs (PMAPs) and other programs/services such as Medicare Part D. Prior studies indicate medication assistance programs may decrease patients' out-of-pocket expenses and increase medication adherence, which in turn may improve health outcomes. ${ }^{14-18}$ For example, a formalized program located at an outpatient pharmacy and designed to help liver transplant recipients acquire post-transplant medications decreased nonadherence from $25 \%$ to $10 \% .{ }^{16}$ However, apart from a very few studies, there is a dearth of information available in the literature regarding medication assistance programs serving solid-organ transplant recipients. The purpose of the current study was to describe the Medication Access Program (MAP) and the population of solid-organ transplant recipients it serves. An additional objective was to compare the characteristics of recipients whose MAP enrollment was continued versus those who were discontinued during the annual re-enrollment period. This assessment was to determine if there are clear risk factors for failing to renew this important health care service. Identification of such risk factors would enable health care professionals to intervene to facilitate uninterrupted program services.

\section{Methods}

\section{Program description}

MAP has its main office located on the campus of Georgia Regents University (GA, USA). Its mission is to provide medication access to solid-organ transplant recipients who reside in the state of Georgia in the US. Transplant recipients are enrolled in MAP based on a referral from a MAP pharmacist or another health care professional/transplant team member, and this referral for MAP enrollment may occur at any time post-transplant. To enroll in MAP, a solid-organ transplant recipient completes an application which includes information about demographics, health care coverage, income, and medication regimen. The applicant is also asked to provide financial records such as tax forms to substantiate income level, and to sign consent and health information disclosure forms.

A MAP medication financial specialist located in MAP's main office reviews the application to verify an applicant's eligibility for program enrollment; consultations between medication financial specialists and individuals referred to MAP typically take place via telephone. Since enrollment into PMAPs and other medication assistance programs/services is generally based on income/financial status, this is also the primary eligibility criteria for MAP enrollment. Once verified, the applicant is officially enrolled in MAP. Approximately $45 \%$ of individuals referred to MAP complete the enrollment process. Following enrollment, MAP provides education on the availability of medication assistance programs and assists transplant recipients in enrolling into these programs (eg, PMAPs, Medicare Part B, Medicare Part D, various foundation programs), including completing the necessary application paperwork. This study was approved by the Human Assurance Committee at Georgia Regents University.

\section{Data collection}

To maintain enrollment in MAP, patients must complete a renewal application on an annual basis. The renewal application is similar to the initial enrollment application, requiring data on demographics (eg, age, marital status, donor type, type of transplant, disability), income, monthly 
medical expenses, private health care coverage, Medicare eligibility, Medicare Part D enrollment, Medicaid eligibility, and benefits (Veterans' Administration, social security, disability) eligibility. In the current study, we collected this data from the renewal applications for 2012 and 2011 (for those who did not return the 2012 renewal applications). We then compared the characteristics of those who renewed their MAP enrollment in 2012 (referred to as "continued recipients") and those who were discontinued because they did not return the 2012 renewal application (referred to as "discontinued recipients"). We also examined recipient records for 2008-2011 to determine the number of times recipients had been previously discontinued as a result of not returning the annual renewal application (note, recipients are eligible to re-enroll in MAP after they are discontinued, provided all required documentation is completed).

\section{Statistical analysis}

Statistical analyses were performed using IBM SPSS Statistics 20.0 (IBM Corporation, Armonk, NY, USA). Participant characteristics were summarized by frequencies for categorical variables, and by means and standard deviations for continuous variables. Chi-square analyses were conducted to examine independency between categorical characteristics and group (continued recipients versus discontinued recipients). Student's $t$-test for independent samples were used to assess differences between group and continuous variables (age, annual gross income, monthly medical expenses). Multivariate stepwise logistic regression analysis was conducted to determine the value of demographics, income variables, and health care coverage variables as predictors of MAP continuation status (continued recipients versus discontinued recipients). The a priori significance level was 0.05 .

\section{Results}

There were 246 recipients eligible for MAP re-enrollment and included in the study. The majority of recipients had deceased donor transplants $(57.3 \%)$, renal transplants (55.7\%), qualified for Medicare (67.9\%), did not qualify for Medicaid (69.9\%), and did not have private health care coverage $(63.8 \%)$. Mean age of recipients was 51.74 years \pm 12.31 years, and mean annual gross income was US\$13,821.98 \pm US\$10,213.32 (Table 1). More than $83 \%$ of the total sample reporting income data (139 of 166) had annual gross incomes below the 2012 federal poverty guideline ${ }^{19}$ for a family of four, $\$ 23,050$. The majority of recipients (79.7\%) also returned their 2012 renewal applications and were classified as "continued recipients", while a minority of $20.3 \%$ did not return their 2012 renewal applications and were classified as "discontinued recipients".

As displayed in Table 1, there were no significant differences between continued recipients and discontinued recipients on any factor under consideration, with two exceptions. Significantly more continued recipients qualified for Medicare compared to discontinued recipients $\left(\chi^{2}=9.236, P=0.002\right)$. Discontinued recipients had a significantly greater number of past discontinuations compared to continued recipients $\left(\chi^{2}=9.18, P=0.01\right)$. In the logistic regression analysis, Medicare eligibility was the only variable significantly associated with continuation status (ie, continued recipients were more likely to qualify for Medicare), accounting for $18.3 \%$ of the variance in the model (adjusted $\left.R^{2}=0.183, P=0.001\right)$. The regression model was as follows:

Continuation status $=0.462+$ Medicare eligibility $(-0.388)$.

Continuation status was coded as $0=$ continued recipient and $1=$ discontinued recipient; Medicare eligibility was coded as $0=$ no and $1=$ yes.

\section{Discussion}

MAP is funded by the not-for-profit Carlos and Marguerite Mason Trust, and its target population includes underserved (ie, low income), solid-organ transplant recipients. Since its 1999 inception, MAP has helped over 765 recipients receive more than $\$ 48$ million in immunosuppressive and other medications, at no cost to recipients. MAP's program objectives are to: ${ }^{20}$

- Increase statewide accessibility of prescription medication to individuals who have received a kidney, liver, heart, lung, or pancreas transplant;

- Promote awareness of medication assistance programs to Georgia's transplant recipients and health care professionals;

- Increase medication adherence.

To accomplish these objectives, MAP: 1) provides education to solid-organ transplant recipients and health care professionals regarding medications and the availability of medication assistance programs; and 2) assists recipients and their health care providers in the process of enrolling into medication assistance programs. Beyond enrollment into appropriate medication assistance programs, the MAP staff also includes two clinical pharmacists, and medication therapy management services are provided on a monthly basis for each MAP patient (usually in outpatient clinic settings). The MAP pharmacists: review drug therapy, including IST and medications to treat comorbid conditions; 
Table I Medication Access Program solid-organ transplant recipient characteristics

\begin{tabular}{|c|c|c|c|c|}
\hline Characteristics & $\begin{array}{l}\text { All recipients } \\
\text { n (\%) }\end{array}$ & $\begin{array}{l}\text { Continued patients } \\
\text { n (\%) }\end{array}$ & $\begin{array}{l}\text { Discontinued patients } \\
\text { n (\%) }\end{array}$ & $P$-value ${ }^{a}$ \\
\hline Sex & & & & 0.240 \\
\hline Female & 91 (37.0\%) & 76 (38.8\%) & $15(30 \%)$ & \\
\hline Male & II (47.6\%) & 90 (45.9\%) & 27 (54\%) & \\
\hline Missing & 38 (15.4\%) & $30(15.3 \%)$ & $8(16 \%)$ & \\
\hline Race/ethnicity & & & & 0.865 \\
\hline African American & $103(41.9 \%)$ & $83(42.3 \%)$ & $20(40 \%)$ & \\
\hline $\begin{array}{l}\text { American Indian/ } \\
\text { Alaska Native }\end{array}$ & $2(0.8 \%)$ & $\mathrm{I}(0.5 \%)$ & I (2\%) & \\
\hline Asian & $8(3.3 \%)$ & 7 (3.6\%) & I (2\%) & \\
\hline Hispanic & $13(5.3 \%)$ & II (5.6\%) & $2(4 \%)$ & \\
\hline White & $82(33.3 \%)$ & $65(33.2 \%)$ & $17(34 \%)$ & \\
\hline Other & I $(0.4 \%)$ & I $(0.5 \%)$ & 0 & \\
\hline Missing & 37 (I5.0\%) & $28(14.3 \%)$ & $9(18 \%)$ & \\
\hline Marital status & & & & 0.852 \\
\hline Divorced & $6 \mathrm{I}(24.8 \%)$ & 48 (24.4\%) & $13(26 \%)$ & \\
\hline Married & $89(36.2 \%)$ & $73(37.2 \%)$ & $16(32 \%)$ & \\
\hline Single & 77 (31.3\%) & $59(30.1 \%)$ & $18(36 \%)$ & \\
\hline Widowed & $16(6.5 \%)$ & $13(6.6 \%)$ & $3(6 \%)$ & \\
\hline Missing & $3(1.2 \%)$ & $3(1.5 \%)$ & 0 & \\
\hline Donor type & & & & 0.486 \\
\hline Deceased & I4I (57.3\%) & 114 (58.2\%) & 27 (54\%) & \\
\hline Living & $46(18.7 \%)$ & $35(17.9 \%)$ & II (22\%) & \\
\hline Missing & $59(24.0 \%)$ & $47(24.0 \%)$ & $12(24 \%)$ & \\
\hline Type of transplant & & & & 0.869 \\
\hline Heart & $22(8.9 \%)$ & $16(8.2 \%)$ & $6(12 \%)$ & \\
\hline Kidney & $137(55.7 \%)$ & $112(57.1 \%)$ & $25(50 \%)$ & \\
\hline Liver & $32(13.0 \%)$ & $25(12.8 \%)$ & $7(14 \%)$ & \\
\hline Lung & $6(2.4 \%)$ & $4(2.0 \%)$ & $2(4 \%)$ & \\
\hline Pancreas & I (0.4\%) & I (0.5\%) & 0 & \\
\hline Kidney/liver & $2(0.8 \%)$ & $2(1.0 \%)$ & 0 & \\
\hline Kidney/pancreas & $9(3.7 \%)$ & $7(3.6 \%)$ & $2(4 \%)$ & \\
\hline Missing & 37 (I5.0\%) & $29(14.8 \%)$ & $8(16 \%)$ & \\
\hline Medicare eligible? & & & & 0.002 \\
\hline Yes & 167 (67.9\%) & $142(72.4 \%)$ & $25(50 \%)$ & \\
\hline No & $64(26.0 \%)$ & $43(21.9 \%)$ & $21(42 \%)$ & \\
\hline Missing & $15(6.1 \%)$ & II (5.6\%) & $4(8 \%)$ & \\
\hline Enrolled in Medicare Part D? & & & & 0.099 \\
\hline Yes & $104(42.3 \%)$ & $91(46.4 \%)$ & $13(26 \%)$ & \\
\hline No & $89(36.2 \%)$ & $70(35.7 \%)$ & $19(38 \%)$ & \\
\hline Missing & $53(21.5 \%)$ & 35 (I7.9\%) & $18(36 \%)$ & \\
\hline Medicaid eligible? & & & & 0.243 \\
\hline Yes & 27 (II.0\%) & $19(9.7 \%)$ & $8(16 \%)$ & \\
\hline No & $172(69.9 \%)$ & 138 (70.4\%) & $34(68 \%)$ & \\
\hline Missing & $47(19.1 \%)$ & $39(19.9 \%)$ & $8(16 \%)$ & \\
\hline Private health care coverage? & & & & 0.360 \\
\hline Yes & $4 \mathrm{I}(16.7 \%)$ & $35(17.8 \%)$ & $6(12 \%)$ & \\
\hline No & $157(63.8 \%)$ & $124(63.3 \%)$ & $33(66 \%)$ & \\
\hline Missing & $48(19.5 \%)$ & $37(18.9 \%)$ & II (22\%) & \\
\hline Disabled? & & & & 0.147 \\
\hline Yes & I 44 (58.5\%) & $119(60.7 \%)$ & $25(50 \%)$ & \\
\hline No & $61(24.8 \%)$ & $45(23.0 \%)$ & $16(32 \%)$ & \\
\hline Missing & $4 \mathrm{I}(16.7 \%)$ & $32(16.3 \%)$ & $9(18 \%)$ & \\
\hline Disability benefits? & & & & 0.071 \\
\hline Yes & II 4 (46.3\%) & 96 (49.0\%) & $18(36 \%)$ & \\
\hline No & $101(41.1 \%)$ & 75 (38.3\%) & $26(52 \%)$ & \\
\hline Missing & $31(12.6 \%)$ & $25(12.8 \%)$ & $6(12 \%)$ & \\
\hline
\end{tabular}


Table I (Continued)

\begin{tabular}{|c|c|c|c|c|}
\hline Characteristics & $\begin{array}{l}\text { All recipients } \\
\text { n (\%) }\end{array}$ & $\begin{array}{l}\text { Continued patients } \\
\text { n (\%) }\end{array}$ & $\begin{array}{l}\text { Discontinued patients } \\
\text { n (\%) }\end{array}$ & $P_{\text {-value }}{ }^{a}$ \\
\hline Social security benefits? & & & & 0.296 \\
\hline Yes & $96(39.0 \%)$ & $80(40.8 \%)$ & $16(32 \%)$ & \\
\hline No & I I 6 (47.2\%) & $90(45.9 \%)$ & $26(52 \%)$ & \\
\hline Missing & $34(13.8 \%)$ & $26(12.3 \%)$ & $8(16 \%)$ & \\
\hline Veterans' Administration benefits? & & & & 0.567 \\
\hline Yes & $3(1.2 \%)$ & $2(1.0 \%)$ & I (2\%) & \\
\hline No & $230(93.5 \%)$ & I84 (93.9\%) & $46(92 \%)$ & \\
\hline Missing & $13(5.3 \%)$ & $10(5.1 \%)$ & $3(6 \%)$ & \\
\hline Number of previous discontinuations & & & & 0.010 \\
\hline 0 & $209(85.0 \%)$ & 173 (88.3\%) & $36(72 \%)$ & \\
\hline I & $29(11.8 \%)$ & $19(9.7 \%)$ & $10(20 \%)$ & \\
\hline 2 & $8(3.3 \%)$ & $4(2.0 \%)$ & $4(8 \%)$ & \\
\hline Mean age $\pm S D$ & $51.74 \pm 12.31$ & $52.32 \pm 12.0$ & $49.48 \pm 13.38$ & 0.182 \\
\hline Mean annual gross income $\pm S D$ & $\$ 13,821.98 \pm \$ 10,213.32^{b}$ & $\$ 13,556.72 \pm \$ 9,545.15^{c}$ & $\$ 15,129.32 \pm \$ 13,154.1 I^{d}$ & 0.552 \\
\hline Mean monthly medical expenses \pm SD & $\$ 797.23 \pm \$ 2,277.02$ & $\$ 674.70 \pm \$ 2,040.38$ & $\$ 1,363.41 \pm \$ 3,133.58$ & 0.140 \\
\hline
\end{tabular}

Notes: ${ }^{\text {TT }}$ The $P$-values represent the comparison between the continued recipients and the discontinued recipients; ${ }^{\mathrm{b}} \mathrm{more}$ than $83 \%$ of the total sample reporting income data (I39 of 166) had annual gross incomes below the 2012 federal poverty guideline ${ }^{19}$ for a family of four, $\$ 23,050$; ' $\mathrm{more}$ than $86 \%$ of continued recipients reporting income data (I I 9 of I 38) had annual gross incomes below the 2012 federal poverty guideline ${ }^{19}$ for a family of four, $\$ 23,050$; ${ }^{d}$ more than $71 \%$ of discontinued recipients (20 of 28 ) had annual gross incomes below the 2012 federal poverty guideline ${ }^{19}$ for a family of four, $\$ 23,050$.

Abbreviation: SD, standard deviation.

identify, prevent, and respond to problems related to medications; address medication information questions; and make therapeutic recommendations by contacting the prescribing physician and other health care professionals involved in care. ${ }^{18}$ Additionally, a MAP clinical pharmacist who works in the Georgia Regents University Renal Transplant Clinic performs similar clinical services with MAP patients on a day-to-day basis. ${ }^{18}$ The goal of MAP's medication therapy management and clinical pharmacy services is to improve medication adherence and health outcomes.

Excluding missing data, MAP's patient population is predominately composed of males and African Americans who received renal transplants, are Medicare eligible, and are generally below the 2012 federal poverty guidelines for a family of four $(\$ 23,050) .{ }^{19}$ Indeed, more than $83 \%$ of the sample who reported income data (139 of 166) had annual gross incomes below the federal poverty guideline. Additionally, the average medical expenses of recipients generally approximate or exceed their average annual gross income. This is consistent with prior studies concerning transplant recipients' socioeconomic status and ability to pay for medications. ${ }^{11,12}$ For example, a survey of US renal transplant centers conducted by Evans et al found that $70 \%$ of centers reported transplant recipients had very- or extremely serious problems paying for medications, with $47 \%$ of centers noting that more than $40 \%$ of their patients had difficulty purchasing IST..$^{21}$ Moreover, $68 \%$ of centers reported graft failures and patient mortality as a result of nonadherence due to IST costs. As demonstrated by this and previous studies, solid-organ transplant recipients, particularly those of low socioeconomic status, are at risk of increased financial burden and decreased medication access. MAP and similar programs are designed to combat the financial challenges faced by transplant recipients and other patient populations to facilitate increased access to needed medication. ${ }^{13-18}$ Such access may, in turn, foster positive outcomes, including decreased graft rejection and improved health-related quality of life. ${ }^{18}$

An additional study objective was to compare the characteristics of recipients whose MAP enrollment was continued versus those who were discontinued during the 2012 annual re-enrollment period. The purpose of this analysis was to identify possible risk factors for failing to renew enrollment, as increased knowledge and understanding of such risk factors may enable MAP staff to intervene during the re-enrollment period to facilitate uninterrupted access to MAP services. Examination of independent variables gleaned from the enrollment application and recipient records found two significant factors in the bivariate analysis. The first was Medicare eligibility, wherein continued recipients were more likely to qualify for Medicare than discontinued recipients (of note, Medicare eligibility was the only significant independent variable in the logistic regression analysis regarding continuation status). We speculate that individuals who qualify for Medicare may be more familiar with the demands of completing applications to continue/renew program eligibility and/or access program benefits. As a result, these transplant 
recipients may be more likely to return their annual MAP renewal applications. The second significant factor in the bivariate analyses was past discontinuations. Discontinued recipients were more likely to have a greater number of past discontinuations compared to continued recipients $(28 \%$ of discontinued patients compared to $12 \%$ of continued patients had at least one past discontinuation). As past behavior is often predictive of future behavior, this finding was unsurprising and suggests health care providers should use historical monitoring to identify high risk patients and implement programs that will facilitate continuity of care. ${ }^{22}$

There are limitations to this study. This was a retrospective analysis of data, and comparison groups were determined by circumstance rather than randomization. As a result, confounding factors cannot be eliminated and causal inference cannot be made. Likewise, missing data on certain factors may impact interpretation of results. Due to feasibility issues regarding data access, outcomes of MAP enrollment such as medication adherence were not examined (although such results have been reported elsewhere for a sub-group of MAP recipients for whom outcomes data were available through the Georgia Regents University Renal Transplant Clinic). ${ }^{18}$ However, as the purpose of the study was descriptive in nature, akin to a case report, a more rigorous design and inclusion of outcomes was beyond the scope and intention of the investigators.

\section{Conclusion}

The goal of MAP is to increase medication access for underserved, low-income solid-organ transplant recipients through education and enrollment into medication assistance programs. MAP recipients who are not Medicare eligible and have a greater number of past discontinuations are more likely not to enroll in continuous care without significant prompting. Improved understanding of recipient behavior regarding re-enrollment into MAP and similar programs may help health care providers develop strategies to intervene with recipients and ultimately facilitate continued access to services.

\section{Acknowledgment}

This study was funded by the Carlos and Marguerite Mason Trust Fund.

\section{Disclosure}

The authors report no conflicts of interest in this work.

\section{References}

1. Dew MA, DiMartini AF, De Vito Dabbs A, et al. Rates and risk factors for nonadherence to the medical regimen after adult solid organ transplantation. Transplantation. 2007;83:858-873.
2. Chisholm MA, Lance CE, Mulloy, LL. Patient factors associated with immunosuppressant therapy adherence in renal transplant recipients. Am J Health Syst Pharm. 2005;62:1775-1781.

3. Ghods AJ, Nasrollahzadeh D. Noncompliance with immunosuppressive medications after renal transplant. Exp Clin Transplant. 2003;1:39-47.

4. Rosenberger J, Geckova AM, van Dijk JP, et al. Prevalence and characteristics of noncompliant behaviour and its risk factors in kidney transplant recipients. Transpl Int. 2005;18:1072-1078.

5. Denhaerynck K, Steiger J, Bock A, et al. Prevalence and risk factors of nonadherence with immunosuppressive medication in kidney transplant patients. Am J Transplant. 2007;7:108-116.

6. Denhaerynck K, Dobbels F, Cleemput I, et al. Prevalence, consequences, and determinants of nonadherence in adult renal transplant patients: a literature review. Transpl Int. 2005;18:1121-1133.

7. Hardinger KL, Hutcherson T, Preston D, Murillo D. Influence of pill burden and drug cost on renal function after transplantation. Pharmacotherapy. 2012;32:427-432.

8. Bentley TS, Hanson SG. 2011 U.S. organ and tissue transplant cost estimates and discussion. Brookfield, WI: Milliman. Available from: http://publications.milliman.com/research/health-rr/pdfs/2011-usorgan-tissue.pdf. Accessed October 25, 2013.

9. Centers for Medicare and Medicaid Services. Medicare coverage of kidney dialysis and kidney transplant services. Baltimore, MD: US Department of Health and Human Services; 2014. Available from: http://www.medicare.gov/Pubs/pdf/10128.pdf. Accessed April 22, 2014.

10. Your Medicare Coverage [webpage on the Internet]. Prescription drugs (outpatient) limited coverage. Baltimore, MD: Centers for Medicare and Medicaid Services. Available from: http://www.medicare.gov/coverage/prescription-drugs-outpatient-limited-coverage.html. Accessed April 22, 2014.

11. Gordon EJ, Prohaska TR, Sehgal AR. The financial impact of immunosuppressant expenses on new kidney transplant recipients. Clin Transplant. 2008;22:738-748.

12. Rodrigue JR, Reed AI, Nelson DR, Jamieson I, Kaplan B, Howard RJ. The financial burden of transplantation: a single-center survey of liver and kidney transplant recipients. Transplantation. 2007;84:295-300.

13. Harmon GN, Lefante J, Roy W, et al. Outpatient medication assistance program in a rural setting. Am J Health Syst Pharm. 2004;61:603-607.

14. Sarrafizadeh M, Waite NM, Hobson EH, Migden H. Pharmacist-facilitated enrollment in medication assistance programs in a private ambulatory care clinic. Am J Health Syst Pharm. 2004;61:1816-1820.

15. Chauncey D, Mullins CD, Tran BV, McNally D, McEwan RN. Medication access through patient assistance programs. Am J Health Syst Pharm. 2006;63:1254-1259.

16. Paris W, Dunham S, Sebastian A, Jacobs C, Nour B. Medication nonadherence and its relation to financial restriction. J Transpl Coord. 1999;9(3):149-152.

17. Schoen MD, DiDomenico RJ, Connor SE, Dischler JE, Bauman JL. Impact of the cost of prescription drugs on clinical outcomes in indigent patients with heart disease. Pharmacotherapy. 2001;21:1455-1463.

18. Chisholm MA, Spivey CA, Mulloy LL. Effects of a medication assistance program with medication therapy management on the health of renal transplant recipients. Am J Health Syst Pharm. 2007;64:1506-1512.

19. 2012 HHS poverty guidelines [webpage on the Internet]. Washington DC: US Department of Health and Human Services. Available from: http:// aspe.hhs.gov/poverty/12poverty.shtml. Accessed November 4, 2013.

20. Medication Access Program [homepage on the Internet]. Augusta, GA: University of Georgia. Available from: http://www.mapuga.com/index. asp. Accessed November 12, 2013.

21. Evans RW, Applegate WH, Briscoe DM, et al. Cost-related immunosuppressive medication nonadherence among kidney transplant recipients. Clin J Am Soc Nephrol. 2010;5:2323-2328.

22. Ouellette JA, Wood W. Habit and intention in everyday life: the multiple processes by which past behavior predicts future behavior. Psychol Bull. 1998; $124: 54-74$. 
Patient Preference and Adherence

Dovepress

\section{Publish your work in this journal}

Patient Preference and Adherence is an international, peer-reviewed, open access journal that focusing on the growing importance of patient preference and adherence throughout the therapeutic continuum. Patient satisfaction, acceptability, quality of life, compliance, persistence and their role in developing new therapeutic modalities and compounds to optimize

Submit your manuscript here: http://www.dovepress.com/patient-preference-and-adherence-journ clinical outcomes for existing disease states are major areas of interest for the journal. This journal has been accepted for indexing on PubMed Central. The manuscript management system is completely online and includes a very quick and fair peer-review system, which is all easy to use. Visit http://www. dovepress.com/testimonials.php to read real quotes from published authors. 